Features

\title{
Design, Introduction, and Extension of Low-Pressure Drip Irrigation in Myanmar
}

\author{
Brent Rowell ${ }^{1,3}$ and Mar Lar Soe ${ }^{2}$
}

AdDITIONAL INDEX wORDs. trickle, microirrigation, treadle pump, low cost, ultralow pressure, Burma

SUMMARY. Drip irrigation is used extensively by both large and small commercial horticultural crop growers in most developed countries where benefits include not only high water use efficiency, but also higher yields, improved product quality, and reduced incidence of foliar disease. Drip systems are still relatively new and expensive in Southeast Asia, and it is primarily wealthier farmers who currently enjoy its benefits. There are also significant perceptual barriers to adoption as many farmers are accustomed to applying copious amounts of water to horticultural crops and are unfamiliar with drip or their crops' actual water requirements. As a nongovernmental organization whose mission is to help boost small farm incomes, International Development Enterprises (IDE) began experimenting with lowpressure, low-cost gravity-fed drip systems in Myanmar (Burma) in 2006. While the basic design was similar to microtube drip systems of the $1960 \mathrm{~s}$, local improvements included filters designed for low pressures, easy-to-use fittings, and inexpensive collapsible header tanks. Our system was optimized for operation on small but commercial-scale plots using pressures as low as 1 psi or only $\approx 1 / 10$ th of that used for conventional drip irrigation. Extension support materials included illustrated installation guides, system design software, videos, testing/filtering of dissolved iron, and easy-to-use water requirement calculators. After hundreds of controlled and farmers' field tests, our locally manufactured drip sets were offered for sale by private dealers throughout Myanmar in 2009. Incremental system improvements coupled with a strong on-farm demonstration and farmer education program resulted in the successful introduction and widespread adoption of drip irrigation in Myanmar.

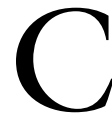

ommercial horticultural crop growers in the United States, Europe, Australia, China, Korea, Brazil, Mexico, South Africa, and the Middle East enjoy the benefits of drip irrigation, which have been described in numerous research and extension publications over the past 40 years. Wellknown benefits include higher yields, improved product quality, and reduced incidence of foliar diseases (Locascio, 2005). Other advantages over conventional irrigation include higher water use efficiency and application uniformity that is unaffected by wind and causes less soil crusting. In some cases, weed pressures are reduced, and farmers can perform weeding and other field operations while irrigating.
Application of plant nutrients through drip systems (fertigation) enables precise fertilizer placement and timing, resulting in better nutrient use efficiency. Drip has also been used successfully on saline soils and with saline groundwater where other irrigation methods are problematic (Hanson et al., 2009). Finally, drip has favorable interactions with plastic mulches, which further boost yields and product quality. Less energy and labor are generally required; shifting to drip has been called the greatest strategic improvement in water use efficiency and energy savings over the past three decades (National Research Council, 2010).

Significant barriers limit the adoption of drip irrigation by small farmers in developing countries. These include high initial system costs (especially if most components are imported), the need for relatively clean or filtered water, and the tendency for emitters to clog with contaminants such as dissolved iron. Even more important are perceptual barriers, which include the apparent complexity of drip systems and the almost instinctual first reaction from farmers that drip will not supply sufficient water for their crops. Some drip components, such as lateral tubing made from linear low-density polyethylene (LLDPE), are also occasionally damaged by rodents or other animals. Overcoming these barriers requires not only appropriate hardware design, but also an equal emphasis on technical support, farmer education, and on-farm demonstration.

Having worked with drip irrigation for 12 years as an extension specialist in the United States before beginning work with IDE in Myanmar (IDE, Denver, CO) in 2006, the senior author understood firsthand drip's benefits after numerous demonstrations and trials with small commercial

\begin{tabular}{llll}
\hline $\begin{array}{l}\text { Units } \\
\begin{array}{l}\text { To convert U.S. to SI, } \\
\text { multiply by }\end{array}\end{array}$ & U.S. unit & SI unit & $\begin{array}{l}\text { To convert SI to U.S., } \\
\text { multiply by }\end{array}$ \\
\hline 0.4047 & $\mathrm{acre}(\mathrm{s})$ & $\mathrm{ha}$ & 2.4711 \\
0.3048 & $\mathrm{ft}$ & $\mathrm{m}$ & 3.2808 \\
0.0929 & $\mathrm{ft}^{2}$ & $\mathrm{~m}^{2}$ & 10.7639 \\
3.7854 & $\mathrm{gal}$ & $\mathrm{L}$ & 0.2642 \\
2.54 & inch(es) & $\mathrm{cm}$ & 0.3937 \\
25.4 & inch(es) & $\mathrm{mm}$ & 0.0394 \\
0.4536 & $\mathrm{lb}$ & $\mathrm{kg}$ & 2.2046 \\
0.0254 & $\mathrm{mil}$ & $\mathrm{mm}$ & 39.3701 \\
1 & $\mathrm{ppm}$ & $\mathrm{mg} \cdot \mathrm{L}^{-1}$ & 1 \\
6.8948 & $\mathrm{psi}$ & $\mathrm{kPa}$ & 0.1450 \\
0.9072 & ton $(\mathrm{s})$ & $\mathrm{Mg}$ & 1.1023 \\
& & &
\end{tabular}


vegetable farmers in Kentucky (Rowell, 1999). Given this background, we did not spend a lot of time comparing drip with conventional irrigation methods as such trials were being conducted with positive results by many researchers in many regions including Southeast Asia (Fandika et al., 2012; Palada and Bhattarai, 2012; Palada et al., 2011). Our goal from the beginning was to develop and promote a drip system, which was both easy to use and affordable to small, commercial-scale fruit, flower, and vegetable growers. Such a system must function well for a plot size of at least 0.1 acre at extremely low system pressures, usually obtained from an elevated water tank. Another objective was to help establish private local manufacturing of all system components. Although the task of developing a commercial low-pressure system (without benefit of motorized pumps) was daunting, knowing the large potential benefits was a motivation enough to make the considerable investments in time and money.

International Development Enterprises is a nonprofit, nongovernmental organization that promotes affordable irrigation technologies for smallholders as its primary tool for raising incomes and reducing poverty using design thinking and a business development approach. IDE's country program in Myanmar became Proximity Designs (Yangon, Myanmar) in 2011 after becoming financially independent from IDE International. Proximity Designs' social enterprise activities focus on

\footnotetext{
This work was generously supported by grants from the Bill and Melinda Gates Foundation, the Mulago Foundation, and the Royal Norwegian Government to IDE and Proximity Designs.

We thank U Aye Tun of the Myanmar Agriculture Service, Martin Pun of the FMI Estates, and U Win Kyaing of the Shwe Dagon Pagoda Foundation for allowing us to use their grounds as our research fields. We would also like to thank real irrigation engineers Jack and Andy Keller, Ryan Weber, and Bob Yoder for technical help and advice. We also acknowledge the very hard work and support from so many current and former IDE/Proximity colleagues including David Klaus, Todd Murphy, Taiei Harimoto, Tun Tun Khine, U Win Maung, Ko Than Htay Zaw, Ko Aung Naing, Ko Zaw Zaw, Htun Thiri Sein, Myat Phyu The, Tin Aye Aung, Khun Mya Maung, Ko Soe Moe Lwin, Yin Yin Oo, Jacquetta Hayes, and Tim Mitzman.

${ }^{1}$ Department of Horticulture, N-318 Agricultural Science North, University of Kentucky, Lexington, KY 40546

${ }^{2}$ East-West Seed International, No. (40/A), Mya Sabal Road, Ma Yan Gone Township, Yangon, Myanmar

${ }^{3}$ Corresponding author. E-mail: browell@uky.edu.
}

creating and marketing affordable products and services for rural households; both organizations use marketbased approaches that treat poor farmers as customers rather than aid recipients. Most of Proximity Designs' products are locally made and sold at production cost, while research, design, marketing, and promotion costs are donor funded.

Myanmar, although currently isolated from its potential export markets, produces large quantities of vegetables to supply its population of $\approx 51$ million people. The country has diverse agroclimatic zones ranging from tropical to temperate and grows an enormous variety of vegetable crops including many that are considered indigenous. The major commercial crops grown in 2007-08 were chili [Capsicum annuum (318,000 acres)], tomato [Solanum lycopersicum $(261,000$ acres $)]$, onion [Allium cepa $(175,000$ acres $)]$, and potato [Solanum tuberosum (90,000 acres)]; these together with a wide variety of other crops comprise a total vegetable production area of $\approx 1.8$ million acres (Maung Maung Yi, 2009).

Motorized pumps were unaffordable to most small farmers in the first decade of the 21 st century and the electricity grid still does not extend to the majority of Myanmar's villages; it is therefore not surprising that in most cases commercial horticultural crops were irrigated by hand with large sprinkler cans (Fig. 1) or by furrow/ flood irrigation. Irrigation with sprinkler cans requires backbreaking and time-consuming labor; our surveys revealed that it was common for small farmers to carry 4-6 t of water on their backs daily to irrigate horticultural crops.

The following is a description of the evolution of a low-cost, lowpressure drip system and how this system has been demonstrated and promoted from 2006 to the present. Our primary goal was to develop and extend a practical and affordable low-pressure system in as short a time as possible; to accomplish this, we used a combination of rapid prototypes and quick field tests or screenings. Customers and end users helped make final judgments regarding suitability and performance through continuous on-farm demonstration followed by both formal and informal feedback surveys. While we have tried to describe 8 years of this work under broad headings of "system design and development," "farmers' field testing and demonstrations," and "local manufacturing, sales, and promotion," it should be understood that some of these activities took place simultaneously.

\section{False starts and first attempts}

Modern commercial drip systems from Netafim Ltd. (Tel Aviv, Israel) were first introduced by company representatives and the Myanmar Agriculture Service in one township in Mandalay Division in 1994 and later by an Israeli-local joint venture in 2006 within a government-organized vegetable production zone in Yangon Division. However, these efforts were soon discontinued or abandoned because of high management requirements and expense in Mandalay, and as a result of iron clogging and other problems in Yangon Division.

When the senior author arrived in Myanmar in 2006 with the task of introducing drip irrigation, it was assumed (even by IDE) that this would be as simple as demonstration and sales of IDE's prepackaged "drip kits" that had been imported from India. But, as we began to work with these kits, it soon became apparent that they were not suited to local horticultural crop production. The prepackaged kit sizes were often too small or too large, but a more serious problem was that main or submain-to-lateral connectors were preinstalled at fixed spacings that did not match the most common

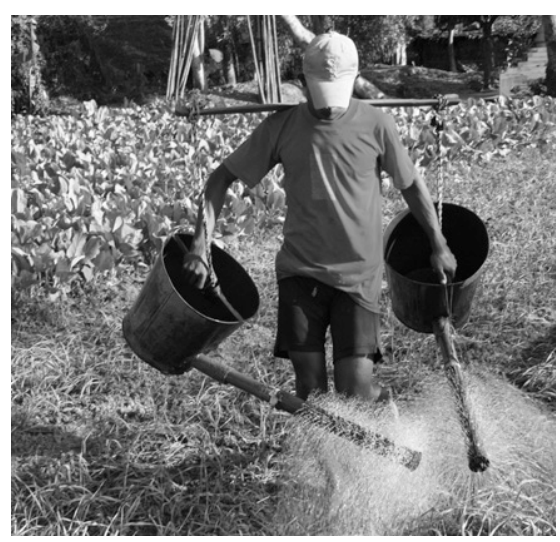

Fig. 1. Traditional sprinkler cans used on horticultural crops throughout Myanmar; a pair of these cans waters $50 \mathrm{ft}(\mathbf{1 5 . 2 4} \mathrm{m})$ of a 3 -ft-wide $(0.9 \mathrm{~m})$ bed and weighs $\approx 70 \mathrm{lb}(31.75 \mathrm{~kg})$ when full. 
row-to-row spacings for horticultural crops in Myanmar. There were also no submain-to-lateral connectors available that could be used with the inexpensive flexible pipe, which was ubiquitous in the country. In addition, importation of IDE drip kits from India was slow, difficult, and expensive. For these reasons the IDE-Indian lateral tubing, microtube emitters, and screen filters were removed from kits on hand and used in our own custom on-farm installations and test plots from 2006 to 2008 , with incremental substitution of our locally made components as they were developed.

IDE-India (New Delhi, India) had developed and popularized garden and small commercial drip kits there in the 1990s and early 2000s. The basic design was an adaptation of an older microtube (spaghetti tube) emitter system first introduced in Israel and the United States in the 1960s (Chapin Watermatics, 1971). Although this type of emitter system has long since been abandoned for field use in developed countries in favor of more convenient (built-in) labyrinth or turbulent flow path emitters, microtube emitters are still used in greenhouses in the United States and elsewhere.

Significant improvements to the microtube system had been made by J. Keller, J.N. Ray, and others in India where use of these systems became widespread through IDE's marketing and promotion efforts (Keller, 2002; Keller et al., 2001). The late Dr. Keller (former Chief Executive Officer, Keller-Bliesner Engineering, Logan, UT, and Professor Emeritus, Utah State University, Logan, UT) was a global authority on irrigation engineering and spent a large part of his professional career helping develop affordable systems for low-income farmers in India and throughout the developing world. Most low-pressure drip systems for developing countries, including Myanmar's, are based on his pioneering work.

\section{System design and development \\ Lateral/emitter screenings}

Somewhat skeptical of the microtube system, we began a series of quick tests of various emitter types/laterals in a commercial vegetable grower's field at Bauk Htaw, an area of leafy greens production within Yangon

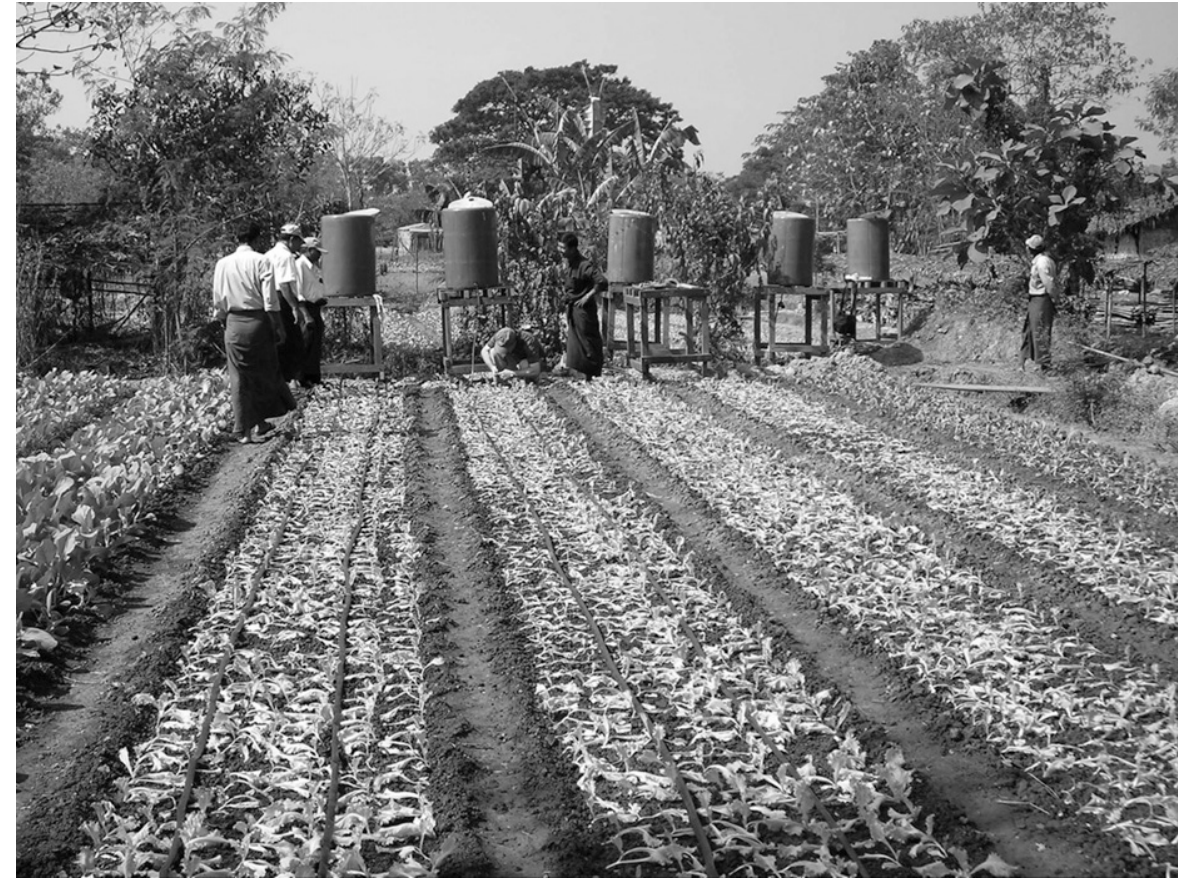

Fig. 2. Low-pressure screening of drip laterals and emitter systems on beds of leaf lettuce at Bauk Htaw in Yangon, Myanmar in Dec. 2006.

(Rangoon) city limits in late 2006 (Fig. 2). These tests were intended to eliminate the worst performers using very low pressures from elevated gravity tanks (height to the bottom of the tanks was $3.5 \mathrm{ft}$, equivalent to $1.5 \mathrm{psi}$ ). Relatively dirty surface water was passed through simple l-inch, 100mesh screen filters mounted between each tank and its drip laterals. Leaf lettuce (Lactuca sativa) was grown (Dec. 2006 to Jan. 2007) followed by leaf mustard [Brassica juncea (Feb. to Mar. 2007)]. Both crops were grown in raised beds $50 \mathrm{ft}$ long and $3 \mathrm{ft}$ wide as is normal farm practice for leafy vegetables in Myanmar. Crop management (other than irrigation) and marketing were the responsibility of the local grower.

Two 50-ft lengths of each lateral/emitter type were used on each bed. Six lateral/emitter systems were tested including three with moderate to high flow rates: $\mathrm{KB}$ brand microtube system (IDE-India), Nepal's (IDE-Nepal, Kathmandu, Nepal) "baffle" emitter system, and a labyrinth flow path emitter product called Adrilite $^{\circledR}$ (Adritec, Aman, Jordon). In the old IDE-India and current Myanmar systems, 8 - to 10 -inch-long microtubes are pushed into thin-walled lateral tubing wherever an emitter is desired. Microtube i.d. was 1 to $1.1 \mathrm{~mm}$, with high flow rates of $\approx 0.5 \mathrm{gal} / \mathrm{h}$ per emitter. Manufacturers for IDE-India later eliminated microtubes in favor of simple prepunched holes at fixed spacings.

The three low-to-moderate flow rate systems tested with labyrinth flow path emitters were T-Tape ${ }^{\circledR}$ (Rivulis Plastro, Kibbutz Gvat, Israel), Chapin Watermatics drip tape [Chapin (Jain Irrigation, Watertown, NY)], and Das drip tape [Das (Das Agroplastics, Pune, India)]. These were also compared with a control plot, which was watered by traditional practice with two 4-gal sprinkling cans (Fig. 1). All plots were watered daily using equal amounts of water. Yield and product quality were measured by harvesting all plants in the bed within a 10 -ft-long subplot. Emitter flow rates from the different systems were measured indirectly by recording the amount of water discharged hourly from each of the 55 -gal plastic drums providing water to the drip systems (Fig. 2).

Open-pollinated leaf lettuce and leaf mustard were grown at equidistant spacings in seven rows/bed. Emitter flow uniformity, while not measured directly, was observed by rating plant uniformity and vigor within the beds under the different drip systems. Any problems with flow or emitter 
clogging were also noted. Although emitters were soon hidden from view under dense plant canopies, it was easy to know when clogging occurred by the lack of flow over time from the gravity tanks and resultant poor plant growth.

LABYRINTH Vs. MICROTUBE. In these tests, the lower flow rate drip laterals generally performed better than high flow rate products (data not shown), although no firm conclusions were possible without further replication. It was obvious that lowto-moderate flow rates from labyrinth flow path emitter products (T-Tape ${ }^{\circledR}$, Das, Chapin) resulted in higher yields and better uniformity of densely planted leafy greens than from IDE-India's $\mathrm{KB}$ brand microtube or IDE Nepal's "baffle" systems with their very high flow rates. Some of the drip systems resulted in yields equal to or slightly higher than sprinkler can watering for leaf lettuce, but not for leaf mustard. However, direct comparisons with sprinkler can watering were beyond the scope of this test.

The reason why low flow rate drip laterals performed better became obvious as the season progressed. Both leaf lettuce and leaf mustard formed solid plant canopies, which completely covered the bed surface, and within these canopies it was easy to see that plants in rows farthest from the high flow rate KB (microtube) and "baffle" emitters were not receiving sufficient water. We believe this to have occurred because of the wide beds and high flow rates. Although soils at this location were medium textured, local hand preparation of beds resulted in a somewhat rough and cloddy soil surface permitting little capillary water movement in the first few inches of soil. Water behaves differently in soil at high and low flow rates; the soil matrix becomes saturated and gravity is the dominant force at high flow rates causing more downward movement of the water column, while water moves more by capillary action through small pore spaces in the soil at lower flow rates, resulting in water, which is pulled in all directions and the formation of a larger wetted area. On coarse-textured soils, the wetted radius increases as drip discharge rates decrease (Cote et al., 2003), which would result in more uniform plant growth across wide beds with lower flow rate emitters.
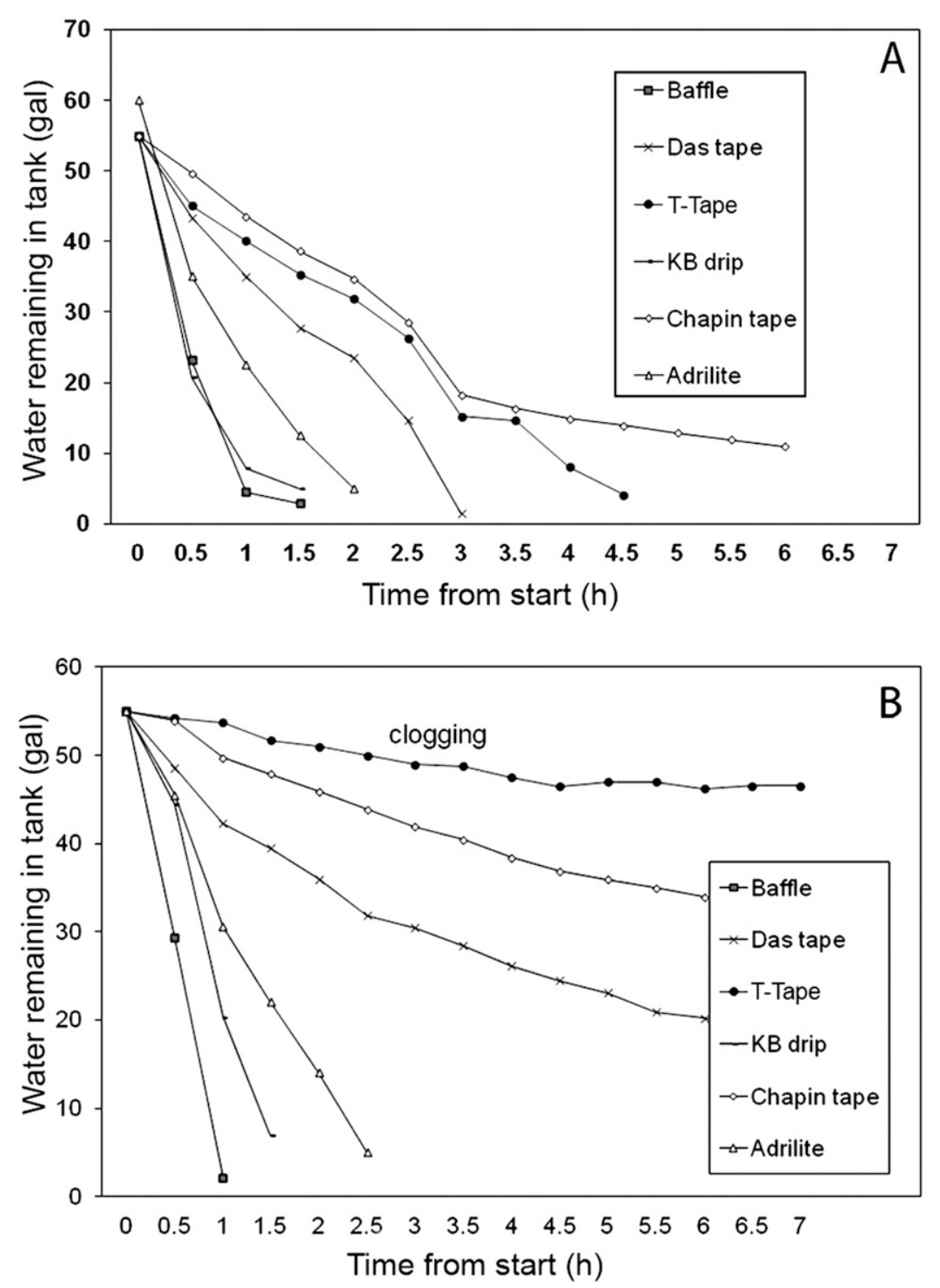

Fig. 3. Water remaining in header tanks 0.5 to $7 \mathrm{~h}$ after starting drip irrigation on leaf lettuce from six different lateral/emitter systems: 1) Baffle emitter laterals (IDE-Nepal, Kathmandu, Nepal), 2) Das tape (Das Agroplastics, Pune, India), 3) T-Tape ${ }^{\circledR}$ (Rivulis Plastro, Kibbutz Gvat, Israel), 4) KB drip microtube system (IDE-India, New Delhi, India), 5) Chapin drip tape (Jain Irrigation, Watertown, NY), and 6) Adrilite ${ }^{\circledR}$ drip laterals (Adritec, Aman, Jordon). Tested in Yangon, Myanmar on 21 Dec. (A) and 27 Dec. (B) 2006; $1 \mathrm{gal}=3.7854 \mathrm{~L}$.

Although we do not consider dense plantings of leafy greens in wide beds particularly suitable for drip because of the extra cost of multiple laterals, they were quick and easy indicators of emitter/drip system performance. However, if we had used only these preliminary findings, we might have selected a labyrinth flow path emitter system as the best choice for Myanmar farmers. As it turned out, there were other selection criteria including resistance to clogging, and more importantly, ease of manufacturing.

Figure $3 \mathrm{~A}$ and $\mathrm{B}$ show water discharge rates for the six drip lateral/emitter systems with leaf lettuce on 21 and 27 Dec. 2006. The $y$-axis indicates the number of gallons remaining in the tanks, while the $x$-axis is the number of hours after beginning irrigation that day; steeper lines indicate faster discharge and higher flow rates. The data from 21 Dec. in Fig. 3A show more or less normal flow rates at very low pressures from all systems. However, discharge rates for $27 \mathrm{Dec}$. shows that some clogging has occurred in three of the labyrinth flow path emitter laterals including T-Tape ${ }^{\circledR}$, Chapin, and, to a lesser degree, Das (Fig. 3B). T-Tape ${ }^{\circledR}$ 
appears to have been partially blocked when irrigation began and completely blocked $4.5 \mathrm{~h}$ later. Although a thorough flushing the following day resulted in better flow from these laterals, the problem persisted.

We continued to measure hourly flow from all treatments for 1 week after harvesting leaf mustard on 10 Mar. By 15 Mar., 90\% of the T-Tape ${ }^{\circledR}$ emitters were clogged and by 16 Mar., $60 \%$ of Chapin emitters were partially or completely clogged together with $90 \%$ of Das lateral emitters. Attempts to clean and reuse these laterals on a third crop were unsuccessful. It should be understood that we purposefully tested these systems under difficult conditions for drip; water at the site was dirty surface water from a nearby city drainage canal. Knowing that most local farmers could not afford expensive sand or disc filters, we used only simple 100-mesh screen filters in these tests. Under these conditions of inadequate filtration, all labyrinth/turbulent flow emitters (with the possible exception of Adrilite $^{\circledR}$ ) became clogged after only two short-season crops over a period of $\approx 70 \mathrm{~d}$.

Although Adrilite ${ }^{\circledR}$ laterals appeared to be more clog resistant than other labyrinth flow path emitter products in our tests, this product has complex injection-molded emitters that are installed during the extrusion process - a manufacturing process impossible to duplicate in Myanmar at the time. While IDE-Nepal's baffle emitter system was also resistant to clogging, we did not like its fixed (prepunched) emitter spacing and very small lateral diameters that could limit its use in larger commercial plantings. For these reasons, we selected the microtube emitter system for further testing as it appeared to be the most robust in terms of clog resistance, was flexible in terms of emitter spacing, and would likely be the easiest to manufacture. We also decided to do further farmers' field testing of Das laterals the following dry season on farms with relatively clean well water.

\section{Whole system testing}

Significant limitations of our custom drip installations using mostly IDEIndia components became apparent after extensive countrywide farmers' field testing during the 2007-08 and 2008-09 dry seasons. Customer satisfaction was disappointing with frequent user complaints of "not enough water" from emitters farthest from the water tanks. In addition, nearly nothing was known regarding the size limits or water application uniformity of these systems for given tank heights/operating pressures, main line diameters, and field arrangements of laterals.

Although some information on low-pressure, gravity-fed drip system performance was available from IDEIndia, most of it was not applicable to local pipe sizes and drip components we used in Myanmar after 2008. We also did not know the best possible arrangement of main, submains, and laterals to achieve maximum application uniformity at very low operating pressures. To answer these and other questions, we conducted over 100 field tests on a level 1-acre vacant plot in Yangon from Mar. to June 2009.

In nearly all of these tests, the "bottom line" dependent variable was the coefficient of uniformity (CU) proposed by J. Keller (2002 and personal communication) as the standard measure of application uniformity for smallholder drip systems. The $\mathrm{CU}$ is derived from the coefficient of variation $(\mathrm{CV})$ of catch can observations. The catch can $\mathrm{CV}$ is a measure of the variability of the amounts of water collected in catch cans placed under drip emitters at different locations within a test field (Fig. 4), and is easily calculated using a hand calculator or spreadsheet as follows:

$$
\mathrm{CV}=\frac{\mathrm{SD}}{q} \times 100
$$

where SD is the standard deviation of the catch can amounts of the population and $q$ the overall average of all catch can observations. The CU is simply $100-\mathrm{CV}$, and therefore a measure of water application uniformity. We used a cU of $80 \%$ as the minimum acceptable value as proposed for smallholder drip and sprinkler irrigation systems in developing countries (Keller, 2002).

Three groups of six catch cans each (18 total) were buried so that water from individual microtubes flowed easily into the containers. The first group of six cans was placed near the end of the first lateral closest to the water tank or main line, the second in the center of a lateral at the center of the plot, while the third was near the end of the last lateral (Fig. 4). Water was collected in the cans for 3 min and measured, after which the CU was calculated and the test repeated.

Independent variables examined in this first series of tests included water tank height, main line diameter, splitting of lateral lines with a center submain, placement of the main line

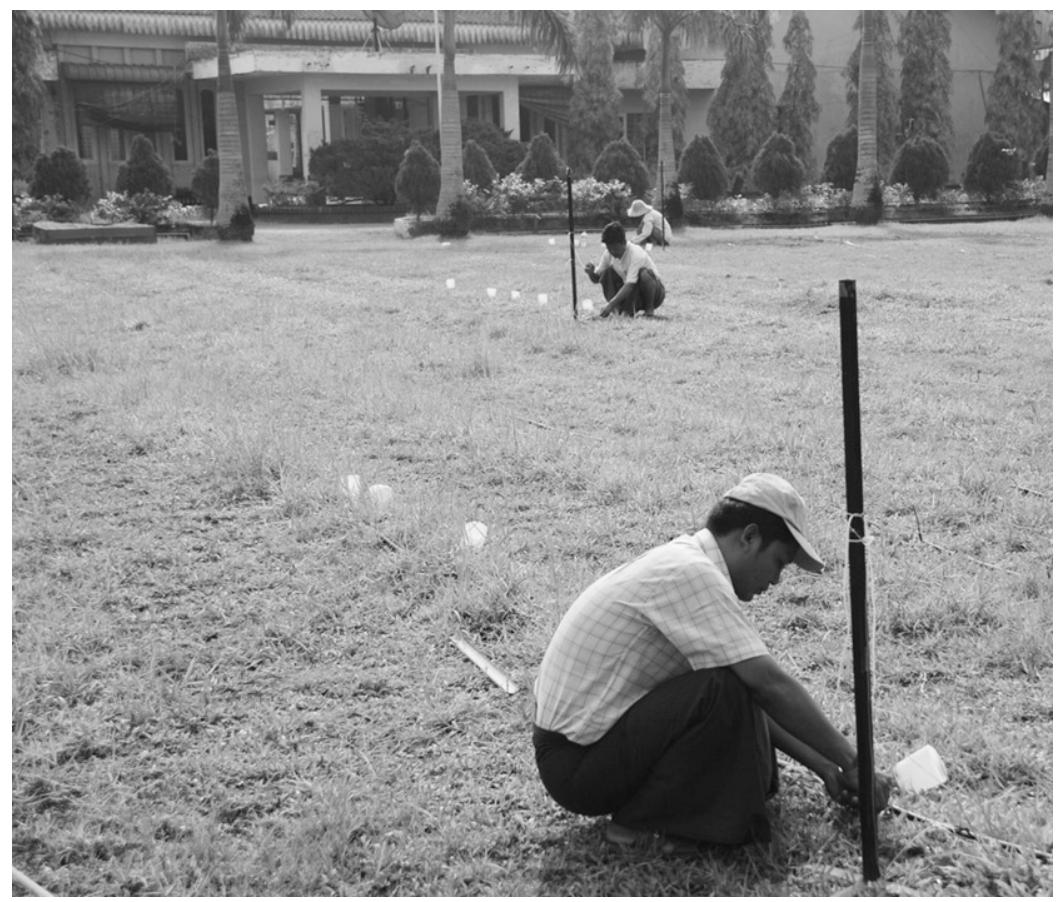

Fig. 4. Catch cans and intravenous tube manometers used in drip system water application uniformity testing in Yangon, Myanmar in 2009. 
( side or center of field), use of a " $\mathrm{T}$ " connector to join the main line to submains, and so on. In all cases, we determined the maximum number of emitters (and length of laterals) that could be used and still maintain a CU of $80 \%$. To do this, we first selected what we considered a reasonable number of emitters/laterals and then increased or decreased this number after each test until the minimum CU was reached.

\section{Water tank to "Water Basket"}

Elevated water tanks used for these tests and for most on-farm installations after 2007 were prototypes of what came to be known as IDE or Proximity Designs "Water Baskets." The concept and initial design of the Water Basket came from collaborations with Stanford University's (Stanford, CA) "Design for Extreme Affordability" graduate classes in 2006 and 2007. The first version consisted of inexpensive plastic tarp material folded and riveted to form cubical 200-gal watertight containers. These Water Baskets, used in our early drip system tests and demonstrations, were mounted atop sturdy 5- to 8-ft-tall bamboo or wooden stands. However, these earlier versions were not entirely self-supporting, and had to be enclosed within bamboo or wooden sidewalls (Fig. 5, left).

Only a summary of the most relevant findings is reported here. After comparing 4-, 6-, and 10-ft tank heights, we chose to use $6 \mathrm{ft}$ (height to bottom of the tank) in conjunction with locally available $1^{1 / 4}$-inch (1.2inch i.d.) flexible pipe for main and/or submains. One-inch (0.9- to 1 -inch i.d.) pipe reduced flow and system performance considerably while $1 \frac{1}{2} 2$-inch flexible pipe did not offer sufficient advantages to justify its high cost for small drip systems. Performance may not have improved with the local $1 \frac{1}{2} 2$ inch pipe in part because of the small diameter Water Basket outlet used in these tests.

Several field arrangements of main, submains, and laterals were compared for best performance under low pressures; results were simplified as "good," "better," and "best" illustrations (Fig. 6), which appeared in the first edition of our installation and users' guide (Rowell and Soe, 2009). These results also led to the design and manufacture of new components for 2009 including two sizes of plastic " $T$ " fittings used to join mains to submains. The tests also revealed significant gains in pressure and flow from removing the

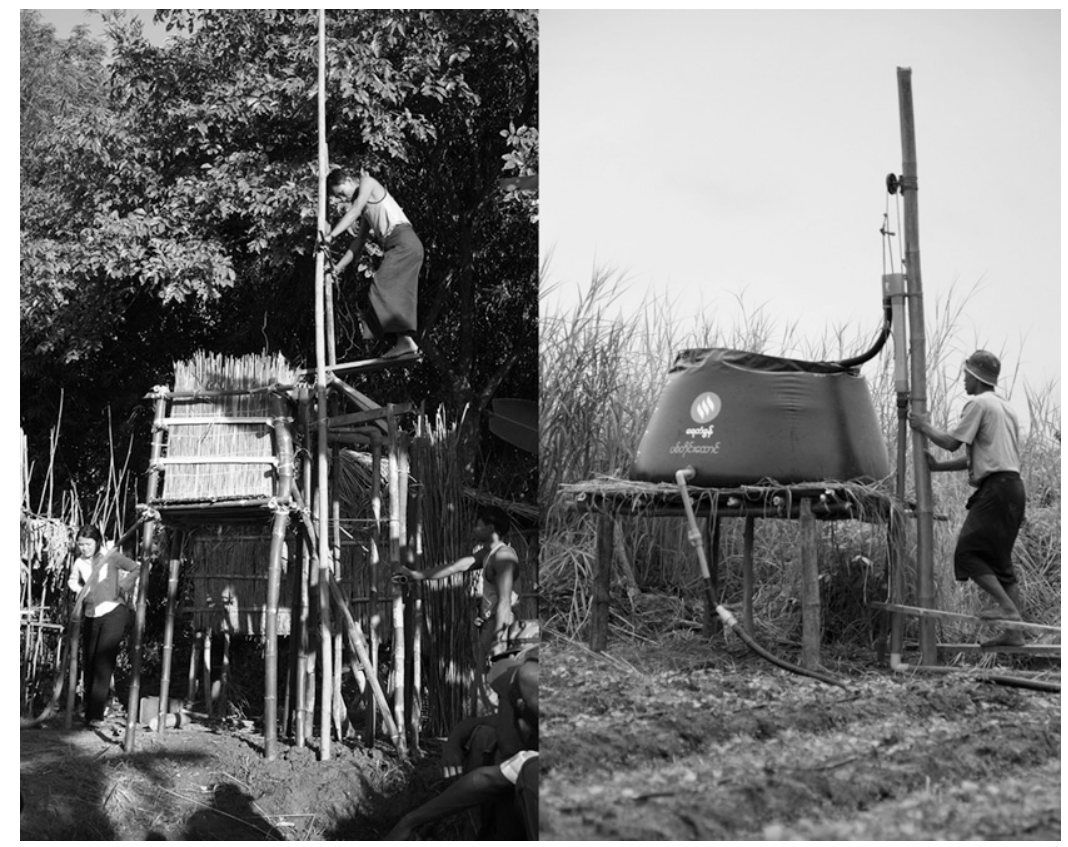

Fig. 5. Old elevated International Development Enterprises-Myanmar (Yangon, Myanmar) foot-operated treadle pump and 200-gal (757.1 L) Water Basket supported by bamboo sidewalls in Myanmar in 2008 (left). Proximity Designs' (Yangon, Myanmar) "Sin Pauq" (baby elephant) elevated pump with treadles on the ground together with Proximity Designs' new self-supporting Water Basket in Myanmar in 2012 (right). ordinary 1 -inch screen filter as was reported by some of our customers. We decided that the advantages of using a simple filter outweighed potential gains in pressure and system size without one; all subsequent guidelines for maximum zone sizes and number of emitters published in our installation guides were obtained from tests that included screen filters. The effect of filter design on flow rate at very low pressures was studied more in depth in the 2010 tests described below.

\section{Component testing}

Although the 2009 tests resulted in a better functioning system that could be optimized for uniformity using different arrangements of mains and submains, further studies were required. In the interim, our 2009 results were shared with J. Keller who observed that we were losing much of our system pressure at some point or points between the elevated tank and the junction of the main line to the first lateral. A series of 80 field tests was subsequently conducted in early 2010 to try and pinpoint the source(s) of these losses and to redesign the system to minimize them.

Unlike previous tests, we did not set up a full drip system but used only a $6 \mathrm{ft}$-high Water Basket and its fittings together with a $100-\mathrm{ft}$ length of $1^{1 / 4^{-}}$ inch local flexible pipe with a ball valve on the end to simulate total system flow. A single 45- $\mathrm{ft}$ lateral with six microtubes at its far end was connected to the main line at a distance of $9 \mathrm{ft}$ from the water tank. Two microtubes were inserted in the main line between the Water Basket and the first lateral $\approx \mathrm{l} \mathrm{ft}$ from the lateral-to-main line connection.

System pressures were measured using the microtubes described above connected to simple manometers made from 6- to 10-ft lengths of transparent tubing sold for medical use (i.e., intravenous or "IV" tubing). The tubing was mounted on vertical stands made from steel angle iron or bamboo with cloth measuring tape attached behind the tubing (Fig. 4). Pressure was measured as the height of the water column in the tubing; measurements were also taken from manometers attached to two of the microtubes at the end of the single lateral.

All 2010 tests were conducted using two system flow rates corresponding to small (average $500 \mathrm{gal} / \mathrm{h}$ 

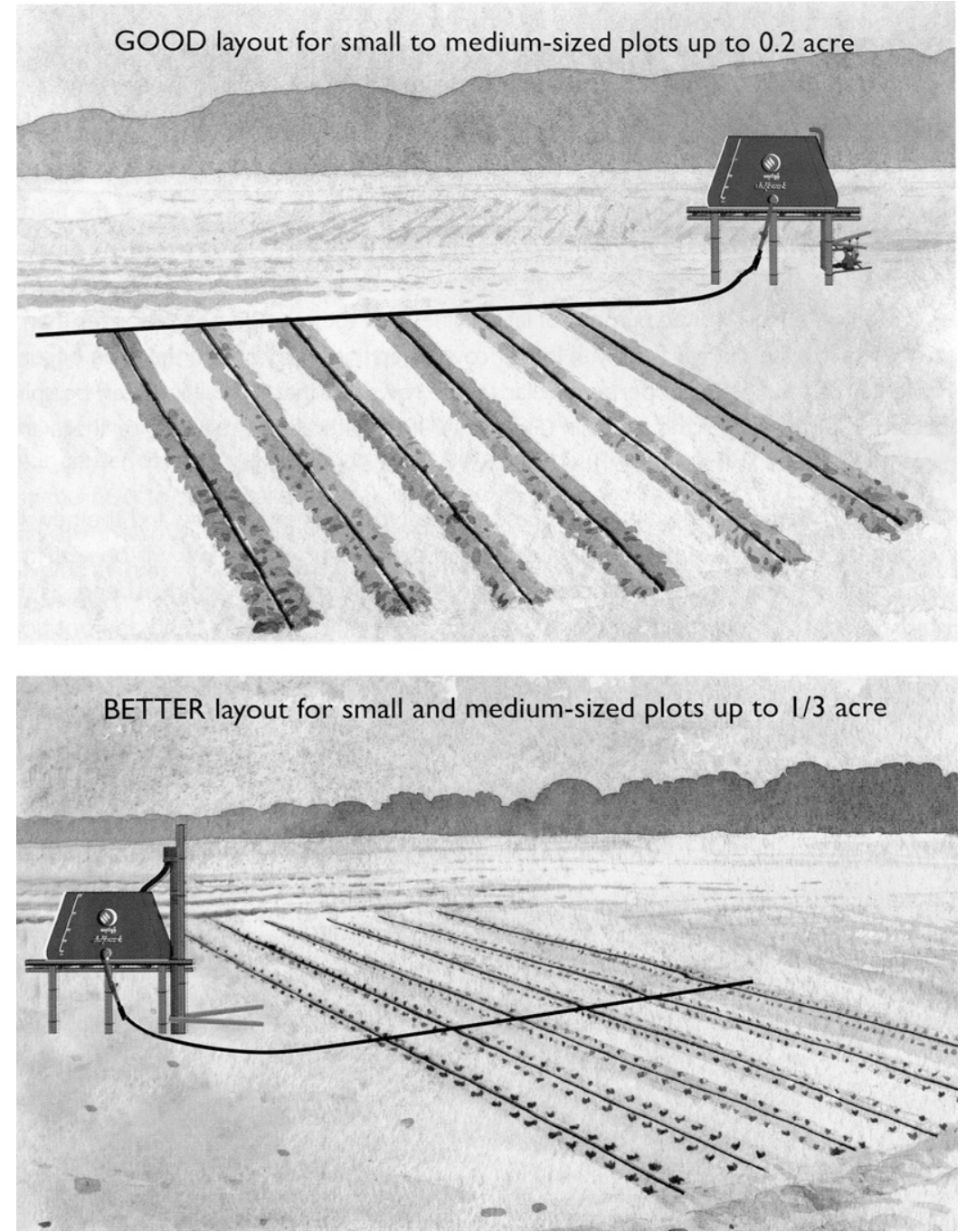

Fig. 6. Simplified low-pressure drip system layouts for plot sizes up to 0.2 acre $[0.08$ ha (maximum 1500 microtube emitters)] and $1 / 3$ acre $[0.13$ ha (maximum 1600 emitters)] using a $3 \mathrm{ft}(0.91 \mathrm{~m})$ water tank outlet height (Rowell and Soe, 2012).

or equivalent to $\approx 1000$ microtube emitters at $0.5 \mathrm{gal} / \mathrm{h}$ per emitter) and medium-sized (average $970 \mathrm{gal} / \mathrm{h}$ or $\approx 1940$ microtubes) drip systems. Flow rates were determined before each test by direct measurement at the far end of the main line. High flow was simulated with an open valve whereas the lower flow rate was simulated by partially closing the valve. Twenty-seven existing and alternative components and fittings of the Water Basket and drip set were tested for their effects on system pressures; only the most important results are summarized here.

Rigid, nominal " 1 -inch" polyvinyl chloride (PVC) pipe (1 $1 / 4$-inch i.d.) resulted in lower head losses than locally made flexible $1^{1 / 4}$-inch pipe (1.2-inch i.d.), at least for the first $2 \mathrm{ft}$ below the Water Basket where the pipe joined the filter. To simplify installations, we chose to use this rigid l-inch PVC for the entire length of pipe required between the Water Basket and ground at which point local $1^{1 / 4}$-inch flexible pipe could be used as the main line without significant additional pressure losses. The old outlet used on Water Baskets was also found to restrict flow and was enlarged to an i.d. of 1.34 inch.

"Low-LOss" FILTER. Many of the 2010 tests were aimed at reducing large pressure losses from our standard l-inch screen filter, which was the same design used by IDE-India and in other small drip systems. Losses were the same with this type of filter regardless of whether it was manufactured in India or Myanmar and amounted to nearly half the total system pressure at low flow rates ["IDE screen 80" (Fig. 7)]. This should not be surprising as these filters were designed for use with higher system pressures than are obtained from gravity systems using only 3 - to 6-ft high header tanks (1.3-2.6 psi). To resolve this problem, we tested three filter designs mounted at the outlet inside the Water Basket and four new prototype screen filters mounted in the usual position between the Water Basket outlet and the ground.

A summary of results comparing pressure losses from some of the filters and prototypes tested is shown in Fig. 7. Although all filters mounted inside the Water Basket performed well without significant losses, we decided not to use this type as they were difficult to remove for cleaning. The straight in-line external filter prototype shown in Fig. 8A looked promising with relatively low pressure losses $(23 \%$ of total head) at low flow rates more typical of our drip system size. However, this design required that the entire filter body be removed from the line to clean the screen element. The prototype in Fig. 8B was designed to overcome this problem and performed just as well, reducing total head losses from $46 \%$ with the ordinary filter to only $18 \%$ [equivalent of no filter in our tests (Fig. 7)] while allowing easy access to the filter element for cleaning.

On the basis of these findings, our design and manufacturing teams developed the final form of the injection molded filter body shown in Fig. $8 \mathrm{C}$ and $\mathrm{D}$, which was used in our drip sets from 2010 to 2013 . While designed for tight friction fits with ordinary rigid $1^{1 / 4}$-inch PVC pipe and small drip systems, local farmers also used it with flexible pipe submains at higher pressures in larger systems using motorized pumps. After changing to this filter, we received no further complaints of pressure losses and almost never saw drip systems in the field with filters removed. The net result from these changes in the filter and other components was that with the same low system pressure we could now effectively irrigate over twice the area as the system used before the 2010-11 dry season. This was equivalent to two full drip sets (1200 emitters) or $\approx 7800 \mathrm{ft}^{2}$ of horticultural crops with a minimum Cu of $80 \%$ and $6 \mathrm{ft}$ Water Basket height. 


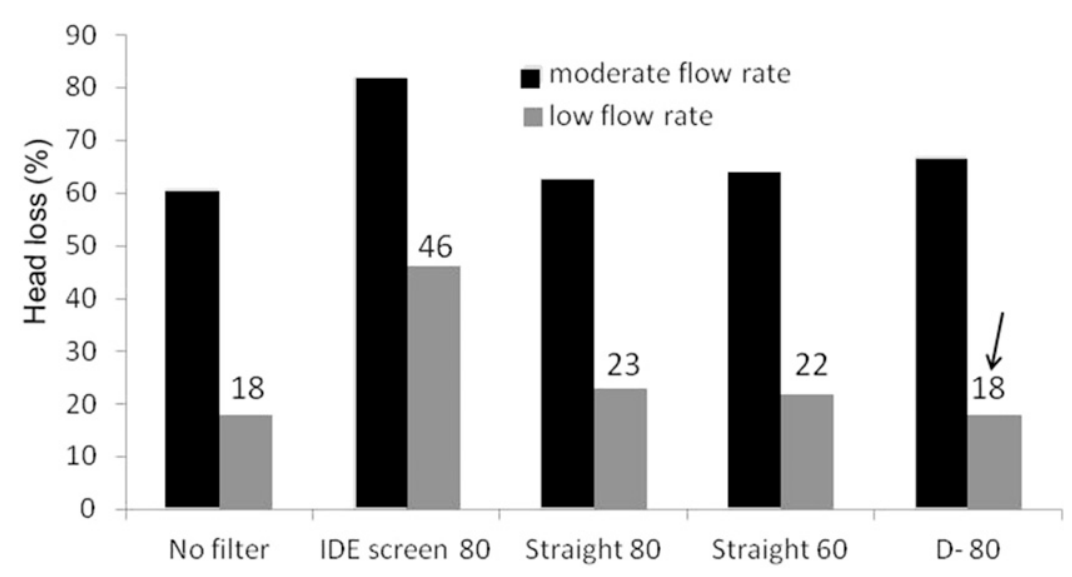

Fig. 7. Relative pressure losses from no filter, ordinary International Development Enterprises (IDE) screen filter (IDE screen 80), straight pipe filter prototypes (Straight 60 and 80), and new filter prototype (D-80) at low and moderate system flow rates in Yangon, Myanmar, in 2010 (see also Fig. 8). IDE screen 80 was an ordinary 80-mesh screen filter manufactured by IDE-Myanmar/Proximity Designs (Yangon, Myanmar) from 2007 to 2009. Straight 60 and 80 filters had 60- and 80-mesh screens, respectively; the D-80 prototype used an 80-mesh screen.

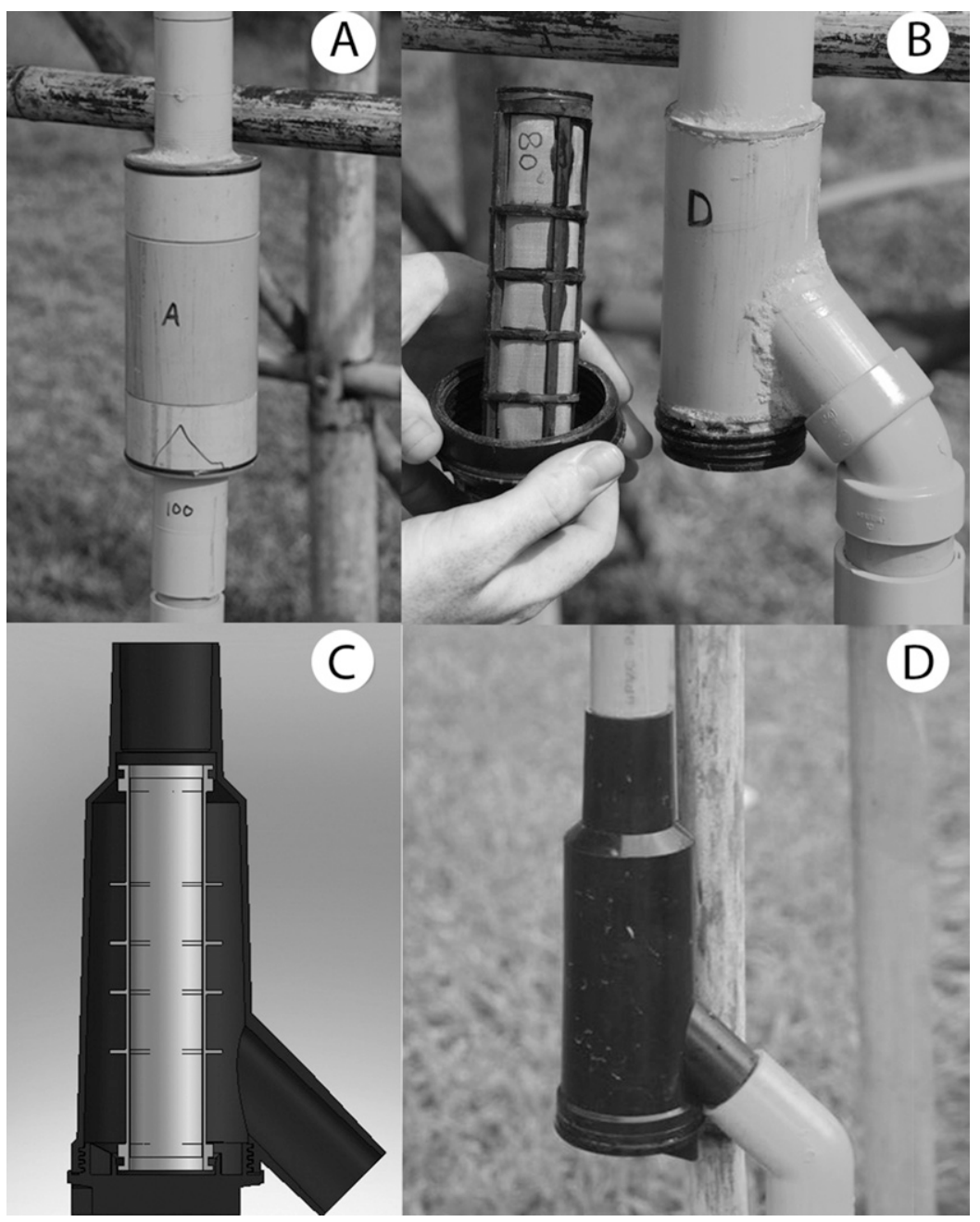

Fig. 8. Screen filter prototypes for low-pressure drip: straight (A), D-80 (B) with 80-mesh screen and the final product "Low-Loss" filter (C and D). Low-Loss filters were manufactured by Proximity Designs (Yangon, Myanmar) from 2010 to 2013.

\section{Low-pressure system design software}

Performance of low-pressure, gravity-fed drip is inherently highly sensitive to small pressure variations. Given the large number of components and fittings affecting performance, and having gone through the laborious process of field testing of each part to optimize the system, we believed a computer software design tool would be extremely useful for improving current and testing new configurations and designs. Software would also enable us to determine the best system configurations for fields larger than the size of two of our drip sets. While a good Excel $^{\odot}$ (Microsoft Corp., Redmond, WA) spreadsheet had been developed for IDE by $A$. Keller (Keller-Bliesner Engineering), it was limited to testing only a few independent variables and was not user-friendly enough for use by our field staff.

Our goal was to develop an easyto-use program both for specialists making component design changes and for drip technicians and field staff designing custom systems for farmers. While the 2010 tests resulted in significant improvements in low-pressure system performance, we did not have time to determine exactly what these improvements meant in terms of system size, maximum number of emitters (i.e., zone size), and field configurations like those shown in Fig. 6. We decided to invest in software development to answer these and other questions rather than begin another time-consuming series of field tests.

Irrigation engineer R. Weber (IDE International) was hired in early 2011 to develop a low-pressure hydraulic model based on field tests in Myanmar. An experimental drip system was installed within a 2 -acre plot of turfgrass in Yangon on the west side of the Yangon River. In addition to the usual IV-tube manometers, in-line pressure sensors with data loggers were used to monitor small changes in system pressure. Measurements also included tests of water application uniformity of microtube emitters.

R. Weber and T.T. Khine (unpublished data) conducted a series of field trials in early 2011 that resulted in a computer model for low-pressure drip systems. The model is being used to develop user-friendly software for personal computers and other 
portable electronic devices. Weber's model uses basic hydraulic principals along with measured characteristics of individual drip system components to show the effects of component design changes, main, submain, and lateral diameters, various field layouts, and effects of inlet pressure on overall system performance. It was used to determine the maximum number of emitters/laterals for different system configurations using new drip components and fittings designed for the 2011-12 and 2012-13 dry seasons. The results were published using the simple good, better, best illustrations in our revised installation guides (Fig. 6).

In addition to recording observations for software development, R. Weber and T.T. Khine (unpublished data) tested samples of thinwalled $21 / 2$-inch-diameter layflat for its suitability for use as main and submains in our drip system. This tubing was evaluated in conjunction with our existing drip system components and resulted in further reductions in pressure losses, not only because of its larger diameter but also due to its much smoother inner wall surface compared with local flexible pipe. Both factors dramatically reduced losses from friction within the pipe, especially at higher flow rates in larger systems.

\section{From low- to ultra-low pressure}

Further modeling and field testing in early 2012 revealed that 2 -inchdiameter layflat made from a mixture of LLDPE and low-density polyethylene (LDPE) would be ideal in terms of reducing pressure losses, low cost, and maximum gravity-fed system size. Using a 2 -inch layflat main line, it was confirmed in the field that a tank height of only $2 \mathrm{ft}$ (from tank outlet to ground) or 0.9-1.5 psi was sufficient for uniform water application (CU $\geq 80 \%$ ) through a drip system of the size of the 2011-12 drip set $\left(\approx 4000 \mathrm{ft}^{2}\right)$. A height of only $4 \mathrm{ft}$ or $1.7-2.8$ psi would uniformly irrigate a plot twice the size of that season's set or nearly 0.2 acre with 4 -ft row-to-row spacing used for many commercial horticultural crops in Myanmar.

Two-INCH system. Two-inch layflat (1.9-inch i.d.) was manufactured so as to fit tightly over short lengths of 11/2-inch-diameter local PVC pipe for easy extension or repairs of main and submains. We made the new tubing

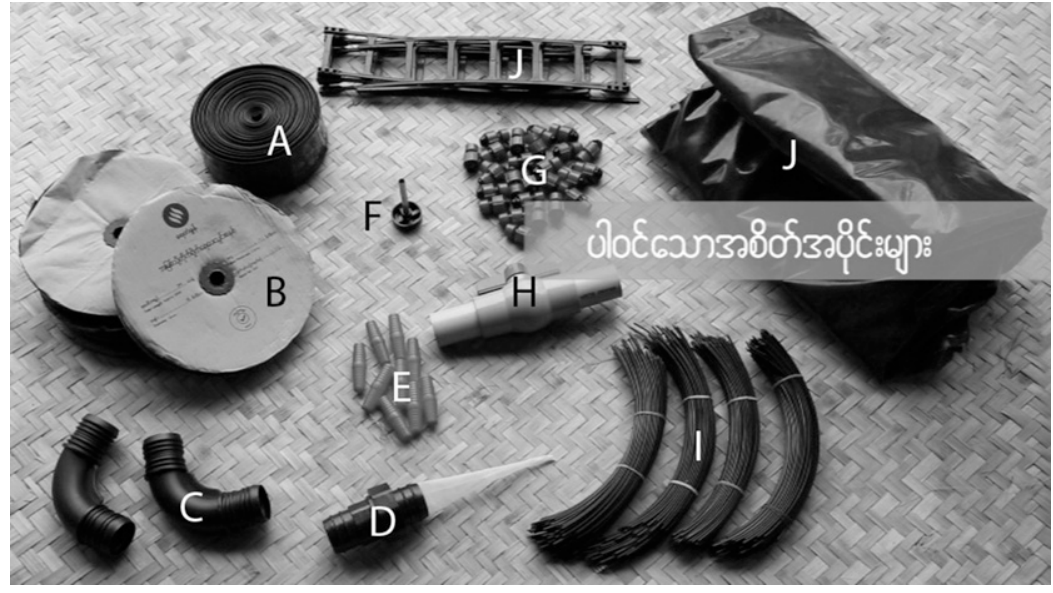

Fig. 9. Proximity Designs' (Yangon, Myanmar) ultra-low-pressure drip set for 2014-15: (A) 2-inch layflat for main/submain, (B) rolls of 5/8-inch lateral tubing, (C) rigid plastic elbows, (D) sock type screen filter for easy installation within 2 -inch layflat, $(E)$ couplers for lateral repairs and extensions, $(F)$ punch for installing connectors in 2 -inch layflat, $(G)$ take-off connectors for joining laterals to 2 -inch layflat, (H) $1^{1 / 2}$-inch ball valve and PVC pipe, (I) microtube emitters. Water Basket $(\mathrm{J})$ is sold separately; all of the above components are made in Myanmar (see also Table 1); 1 inch $=2.54 \mathrm{~cm}$.

with a 12 -mil wall thickness to reduce costs while having a reasonable life expectancy of three to four seasons. The new tubing was manufactured during the Summer of 2012 by a small workshop which had been making our drip lateral tubing using similar LLDPE/ LDPE recipes for both products.

The new layflat was not only half the cost of the local flexible pipe we had been using, but was extremely compact and could now be included as part of a complete small plot drip set (Fig. 9A). But changing to thinwalled layflat and an all 2 -inch system required redesign of almost all other components including take-off fittings for connecting laterals to mains/submains, filter, and the Water Basket outlet; these design changes were made over the next 2 years.

New connections. The first component slated for redesign in 2012 was the take-off connector used to join laterals to mains or submains. Design specifications included not only a stepped connection to accommodate manufacturing variations in lateral tubing, but also a nonleaking seal for thinwalled layflat and locking rings for use with motorized pumps at higher pressures. While six different off-the-shelf connectors from Thailand and the United States were tested with the new layflat, none were designed for thinwalled tubing and none could be used without excess leakage. All were tested at pressures up to 15 psi for suitability for use with both gravity and enginepressurized systems. We eventually made a successful prototype using a widescrew-type ring, which provided more sealing surface area and with a smaller gap between the insertion barb and the stepped connector body; a simple lock ring was also provided to better secure laterals used with motorized pumping systems. These injection molded connectors were locally manufactured for inclusion with the 2 -inch layflat in drip sets for the 2012-13 dry season (Fig. 9G).

NeW WATER BASKeT AND FILTER. Proximity's design team had in the meantime developed a new and robust free-standing 200-gal Water Basket (Fig. 5, right) with an outlet for $1^{1 / 4}$-inch PVC pipe, which was used to accommodate the new LowLoss screen filter used from 2010 to 2013. While we intended to transition to an all 2 -inch system, there was no time to redesign the filter to fit 2inch layflat prior the 2012-13 dry season. The design team later developed a new, inexpensive in-line "sock" filter (Fig. 9D) for 2013-14 based on an early prototype tested by Weber in 2011. The team also developed rigid injection-molded elbows and a new Water Basket outlet for 2013-14; this entirely 2-inch system (Fig. 9; Table 1) is currently available from Proximity Designs in Myanmar (2015). While a minimum Water Basket height of $3 \mathrm{ft}$ is recommended for a single drip set, this ultra-low-pressure system will 
Table 1. Components of Proximity Designs' (Yangon, Myanmar) ultra-low-pressure drip system for the 2014-15 dry season in Myanmar (see also Fig. 9).

\begin{tabular}{|c|c|c|c|}
\hline Item & Units $^{\mathrm{z}}$ & Quantity & Description $^{\mathrm{z}}$ \\
\hline Drip lateral tubing & $300-\mathrm{ft}$ roll & 3 & $\begin{array}{l}\text { 5/8-inch-diameter LLDPE/LDPE }{ }^{y} \text { tubing ( } 8 \text { mil wall thickness), } \\
\text { no emitters }\end{array}$ \\
\hline Microtube emitters & Bundles of 150 & 4 & 10-inch-long microtubes with $1-1.1 \mathrm{~mm}$ i.d. \\
\hline Main/submain pipe & $100-\mathrm{ft}$ roll & 1 & $\begin{array}{l}\text { 2-inch-diameter (1.9-inch i.d.) LLDPE/LDPE layflat, } 12 \text { mil wall } \\
\text { thickness }\end{array}$ \\
\hline Take-off connectors & $\begin{array}{l}\text { Connector with } \\
\text { locking ring }\end{array}$ & 30 & $\begin{array}{l}\text { Injection molded with large }(10 \mathrm{~mm}) \text { i.d.; variable (stepped) o.d. } \\
\text { accommodates variations in lateral tubing diameter. Locking } \\
\text { rings secure laterals for motorized pumps, higher pressures }\end{array}$ \\
\hline Lateral couplers & Coupler & 8 & Extends or repairs $5 / 8$-inch lateral tubing above \\
\hline Punch & & 1 & For installation of take-off connectors in 2 -inch layflat \\
\hline In-line filter & & 1 & Sock-type filter and fittings for installation within 2 -inch layflat \\
\hline $1 \frac{1}{2}$-inch ball valve & & 1 & $\begin{array}{l}\text { Ball valve and short lengths of } 1 \frac{1 / 2}{2} \text {-inch PVC pipe for use } \\
\text { with } 2 \text {-inch layflat above }\end{array}$ \\
\hline Elbows & & 2 & $\begin{array}{l}\text { Injection-molded } 2 \text {-inch elbows for use between Water Basket and } \\
\text { ground }\end{array}$ \\
\hline Installation guide & & 1 & $\begin{array}{l}\text { Illustrated step-by-step installation and users' guide (Rowell and } \\
\text { Soe, 2012); formerly included with every drip set, but now } \\
\text { replaced with an instructional brochure and installation video } \\
\text { (DVD) }\end{array}$ \\
\hline \multicolumn{4}{|l|}{ Sold separately ${ }^{\mathrm{x}}$} \\
\hline $\begin{array}{l}\text { "Sin Pauq"w treadle } \\
\text { pump }\end{array}$ & & & $\begin{array}{l}\text { Mostly PVC construction; easily elevated but with treadles on } \\
\text { ground }\end{array}$ \\
\hline Water basket & & & $\begin{array}{l}\text { Durable and self-supporting walls; } 200 \text { gal capacity with outlet } \\
\text { fittings for easy connections to drip set }\end{array}$ \\
\hline T-fitting & & & Injection molded " $T$ " for use with 2 -inch layflat above \\
\hline
\end{tabular}

also perform well at tank heights of as low as $2 \mathrm{ft}$ or equivalent to $\approx 1$ psi.

\section{Farmers' field testing and demonstrations First introductions, 2007-08}

Ten small, preliminary farmers' field tests were established in Jan.Mar. 2007. In most cases our plots consisted of 300-600 ft of drip laterals applied to a few rows within a farmer's existing commercial planting, which was watered by sprinkler cans, furrow, or elevated tank and hose before drip installation. Old 55-gal steel oil drums on 4- to 6-ft-high stands were used as header tanks to pressurize these systems.

Ordinary l-inch, 100-mesh screen filters from IDE-India were used together with Tape-loc $®$ (Rivulis Plastro) main-to-lateral take-off connectors. Internal diameters of those connectors were only 0.16 inch, which limited overall system performance in these trials. The main line was 1-inch-diameter flexible pipe (recycled PVC) available throughout Myanmar. In some cases IDE's foot-operated treadle pumps were mounted on stands above the drums for easier filling. This required the user to operate the pump from above the tank (Fig. 5, left) or use treadles on the ground linked to the pump by ropes or cables. This practice of filling elevated tanks with treadle pumps existed in some parts of Myanmar even before we began introducing drip. In a few cases, farmers filled tanks by hand from nearby wells. Either the microtube emitter system from IDE-India or Das turbulent flow emitter laterals was used in these tests. Das laterals were used only at sites where wells were the water source.

Results of these first farmers' field trials were mixed, and limitations of the systems tested quickly became apparent. Only about half the farmers were satisfied with system performance and some were quick to stop using it and return to watering with sprinkler cans. Those who had to fill elevated tanks by hand using sprinkler cans or other containers could not see any obvious advantage over watering with the cans directly. We concluded that few farmers would adopt drip for commercial plantings if required to fill elevated tanks by hand. Other farmers observed that water application was not uniform, especially when laterals were over $70 \mathrm{ft}$ long; still others described the common fear that drip could not possibly supply enough water to their plants.

Other serious challenges observed during this season included the old oil drums themselves, which were expensive, relatively small, difficult to transport, and difficult to fit with a proper outlet. Plastic drums were not available in rural areas and were even more expensive than steel drums. Although steel or plastic 55-gal drums were reportedly used with small gravityfed drip systems promoted by IDE-India and other organizations in so-called "drum kits" (Ngigi, 2008; Smeal et al., 2008), we concluded that two of the most critical elements of simple and inexpensive low-pressure drip systems would be cheap and easily elevated water tanks in combination with treadle pumps or other simple means of filling these tanks. 
After completion of the drip lateral screenings and preliminary farmers' field tests described above, we established another 60 demonstrations/ trials on small farms within almost every agroclimatic zone in the country from late 2007 to early 2008 . Locations were chosen according to the interest of our promotion staff and the perceived interest of farmers in those areas. Microtube emitter systems were installed at most sites while drip tape from Das was installed at about one-third of the sites, which had wells as their water source.

Unlike the previous year, elevated water tanks used for many of the 2007-08 on-farm demonstrations were prototypes of what came to be known as the Water Basket. All of these early demonstrations were custom systems, which had to be installed directly by the authors together with local IDE field staff as the technology was virtually unknown to both staff and farmers. Drip was installed on a wide variety of crops, including nine different vegetables, six different fruit crops, four different flower crops, and betel vine (Piper betle).

This second series of on-farm trials with various crops was more successful than the first with over half the farmer cooperators showing genuine interest in drip. An in-depth survey of users conducted in early 2008 indicated that $61 \%$ liked the system and planned to continue using it next dry season. While these results were comparable to $50 \%$ to $60 \%$ continuation rates for first time drip users in Kentucky after similar on-farm demonstrations (Commodity Growers Cooperative Association, 1998), there were still perceptual and performance problems with the new Myanmar system. Our survey indicated that the primary concern of $40 \%$ of new users was insecurity about the amounts of water applied (i.e., they did not think drip could provide as much water as traditional sprinkler cans). Our installation team discussed current and future crop water requirements with farmers who were trying drip, often explaining how equal amounts of water could be applied with drip as with traditional watering methods.

There were also cases of lack of application uniformity, usually resulting from less flow from emitters farthest from the water tank. In addition, we recognized the urgent need for more drip irrigation training for field staff and for drip-related educational tools and materials to use in conjunction with a strong and ongoing onfarm demonstration program.

An unexpected and frustrating hardware problem was the variable i.d. of lateral tubing purchased from IDE-India. While reportedly conforming to the international standard $5 / 8$-inch diameter, individual $100-\mathrm{m}$ rolls of tubing varied widely, so much so that laterals would often not fit IDE-India's own or other commercial lateral-to-main take-off connectors designed for $5 / 8$-inch tubing. As we began local manufacturing, we quickly discovered that lateral tubing required constant sampling, testing, and vigilance to maintain uniform diameters and wall thickness.

IRON PROBLEMS. A more serious problem was first observed at a tube well site in Hmawbi Township where Das drip laterals had been installed in a farmer's field. Emitters in these laterals became completely blocked with iron oxide precipitate within 1 month of installation; the same problem was observed at another site in Kungyangon. We learned that ferrous iron is fairly common in well water in parts of Myanmar and routinely tested for it after 2008. We feared that without some simple solution to the problem, drip irrigation might not be possible in large areas of the country.

Fortunately, one of our field staff showed us a solution to this problem used by villagers in an area where iron-contaminated drinking water was commonplace. It was well known in that area that drinking water from local wells could be "cleaned" by letting it pass through a simple container holding burned rice husks obtained from a local rice mill. This waste product is widely available from Myanmar rice mills, many of which burn the husks to heat boilers powering century-old stationary steam engines. $\mathrm{Al}$ though the mechanism of iron removal is unknown, the high $\mathrm{pH}$ of the ash together with its high surface area and perhaps even activated carbon are likely involved (Das et al., 2007).

Dissolved iron levels above 1.5 ppm are considered "severe" in terms of clogging hazard for drip irrigation in the United States (Lamont, 2012). Using a commercial iron test kit (model IR-18 for $0-5 \mathrm{mg} \cdot \mathrm{L}^{-1}$; Hach Co., Loveland, CO), we found that a 20-gal container of burned husks could remove very high levels of iron almost instantaneously as water passed through it. In our tests, water with $5 \mathrm{ppm}$ iron was reduced to $0-1 \mathrm{ppm}$ after passing rapidly through the filter.

Taking advantage of this local technique, we manufactured cheap 20-gal containers made of plastic tarp material with porous bottoms; these were filled with burned rice husks and suspended between the pump outlet and Water Basket. Drip is now used extensively with these filters in areas where the problem is severe. Villagers also showed us that well water samples containing high levels of iron will instantly turn black when mixed with green tea or crushed guava leaves (thus eliminating the need for an imported test kit), a technique also known by villagers in parts of rural Thailand (Settheeworrarit et al., 2005).

During the course of the first season, we observed emitter clogging of Das tape, D-tape ${ }^{\circledR}$ (labyrinth flow path emitter tape from Super Products, Bangkok, Thailand), and even microtube emitters from iron precipitates from well water. While in most cases Das and D-tape did not clog when used for a single season with iron-free well water, we decided not to continue to test or promote these labyrinth/turbulent flow path emitter laterals. The decision was made in part not only because of the risk of clogging but also because of the nearterm impossibility of setting up local manufacturing for these or similar built-in emitter products.

\section{Growing satisfaction, 2008-09}

On-farm demonstration was the cornerstone of our drip irrigation promotion program from the beginning, and it was our policy to give an interested farmer a drip set or partial set free-of-charge in a new area in exchange for his or her willingness to take ownership of all other aspects of crop production and marketing while providing us with a minimal amount of feedback. Over 300 such demonstrations and installations were conducted across the country during the 2008-09 dry season. While most of the system components were sold to farmers already convinced of the value of drip, about one-third of new installations were provided free-of-charge to farmers who had never heard of it.

Our user survey conducted at the end of this season clearly indicated growing satisfaction with the product 
and its performance with $79 \%$ now reporting their intention to continue using drip compared with $61 \%$ the previous year. Perceptions also appeared to be changing as now only $10 \%$ of users surveyed reported that drip was not supplying enough water compared with $40 \%$ after the 2007-08 season. Some of these farmers and our staff also benefited from the publication of our first drip irrigation installation and users' guide (Rowell and Soe, 2009), an illustrated booklet with simple start-to-finish instructions on how to install and operate a small lowpressure drip system.

All of our installations now included components that we had designed and manufactured in-country including a simple punch and connector system for joining drip laterals to flexible pipe and an ordinary 1 -inch plastic screen filter. We designed the main or submain-to-lateral connectors both to accommodate variable lateral tubing diameters and for easy installation and good fit in locally available flexible plastic pipe. The connectors were also designed with large i.d. (10 $\mathrm{mm}$ ) to reduce friction losses and increase flow at low pressures. Given the expense and difficulty of importing drip kits and components at the time, we concluded that under these conditions drip irrigation would never become economical and accessible to the majority of Myanmar's small farmers without access to inexpensive locally made products.

\section{How much water?}

From the beginning of our demonstrations, we encountered farmer perceptions that limited adoption. Myanmar farmers seeing-but not yet using - drip irrigation invariably commented that the system could not possibly supply enough water compared with their traditional methods of Asian sprinkler can watering or furrow/ flood irrigation. Most farmers trying drip for the first time could not believe that the relatively low flow observed could supply the needs of the crop; they also had no idea how much water should be applied through a drip system. The on-farm demonstrations together with discussions of crop water needs and drip application rates became important strategies to address these issues. The concept of a water requirement calculator was born in 2009 out of these discussions with farmers and their need for a simple and inexpensive tool to estimate horticultural crop water requirements.

We subsequently designed and constructed circular laminated cardboard "Water Wheel" calculators (Fig. 10) using local 30-year averages of monthly evapotranspiration together with simplified crop coefficients based on either growth stages (vegetables) or percentage of crop canopy cover (fruits and tree crops). Details of the design of these tools will be published in a future paper. The primary purpose of the Water Wheel was to enable field staff to quickly and easily estimate water requirements for the most common fruits and vegetables grown in Myanmar. Field workers could discuss these requirements before, during, or after installation of a drip system, providing farmers with a reasonable estimate or starting point.

\section{Local manufacturing, sales, and promotion}

Made in Myanmar, 2009-10. After implementing significant system improvements based on the early 2009 trials described above, the 2009-10 dry season marked the launch of the first drip set made entirely in Myanmar. The set was designed for installations of $\approx 4000 \mathrm{ft}^{2}$ of vegetables or other horticultural crops with typical $4-\mathrm{ft}$ row-to-row spacings. This was a size we considered large enough for local commercial plantings but small enough to be affordable to smallholder farmers. The cost of the set at the time was $\approx \$ 20$, although farmers had to buy their own flexible pipe for main or submain lines at an additional cost of $\$ 10$ to $\$ 15$, depending on plot size. A
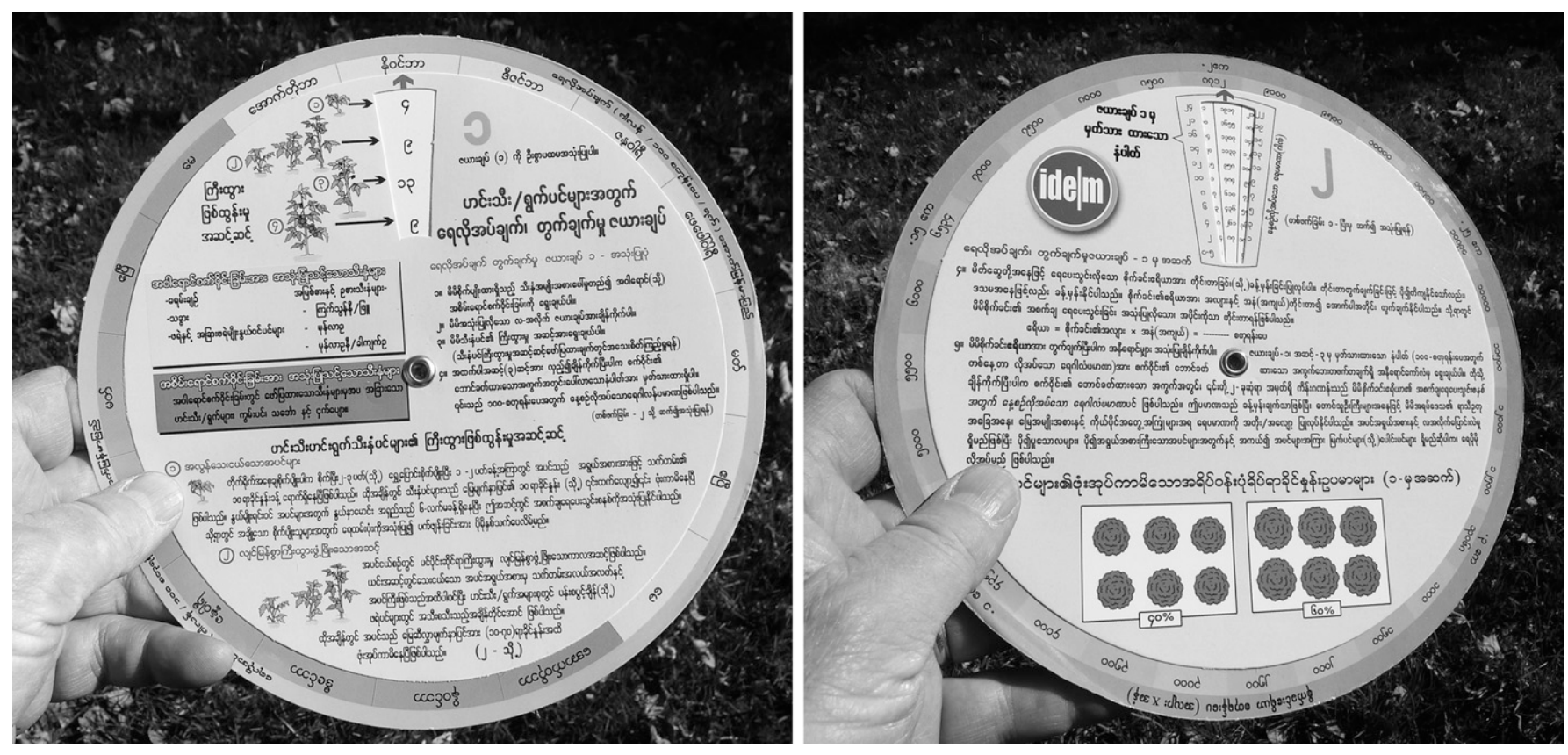

Fig. 10. "Water Wheel" water requirement calculators based on simplified growth stages and long-term evapotranspiration (ET) averages for vegetable crops (left) and on percent canopy cover and ET averages for fruit and tree crops (right). Designed by B. Rowell and made by Proximity Designs (Yangon, Myanmar) from 2009 to 2012. 
$20 \%$ introductory discount was offered that year as an extra incentive to new customers.

IDE-Myanmar's treadle pumps, Water Baskets, and main/submain pipes were sold separately but available through the same field staff and private ag supply shops. It was decided not to package and sell flexible pipe for main or submains as this material was bulky, expensive to transport, and already available in small hardware shops in most parts of the country.

Over 500 of these drip sets were installed by our field staff and agents during this first year of formal sales. It was decided to target former customers who already owned IDE treadle pumps. We assumed that many pump users would have earned extra cash and might be more interested in new products based on their experience with the pump and their relationship with our field staff. These farmers, while not the poorest or the most risk averse, were much more likely to try this radically new and unfamiliar technology than those with absolutely no spare cash (or in debt) or who were unfamiliar with IDE and its products.

This was also the first season in which we began offering product loans, and about half of drip sales were as a result of these loans. But the loan program turned out to be a two-edged sword, requiring a lot of time to administer by field staff who might otherwise have done more drip installations and on-farm demonstrations. Free demonstrations continued only in areas that had not seen a drip system, and the majority of sets were sold by our field staff and dealer shops. Systems were installed by our staff with the full participation of the farmer, or in many cases, the whole family.

Questions about satisfaction with drip and Water Baskets were included in a new customer care survey of 200 drip users conducted at the end of the season. Respondents were given four choices of "unsatisfied," "neutral," "satisfied," or "very satisfied" in answer to the questions, and $88 \%$ were either satisfied $(37 \%)$ or very satisfied $(51 \%)$ with the ease of use of the product. More significantly, 91\% reported that they had recommended drip to a friend or neighbor.

When asked about using hired labor for crop production before and after drip adoption, $59 \%$ reported that they had used hired labor before using drip while only $5 \%$ reported having hired labor after drip adoption. These farmers also reported that, before drip adoption, they made an average of 119 trips to the field daily with sprinkler cans. This amounted to a daily burden of carrying $4 \mathrm{t}$ of water to the field on their backs. We know from this and countless interviews with farmers that the elimination of this heavy labor and the resultant time and energy savings were their primary motivations for adopting drip.

Countrywide EXPANSION, 2010-11. Important changes in system components were implemented for the 2010-11 dry season as a result of tests conducted in Spring 2010. This drip set included the new LowLoss screen filter (Fig. 8C and D) together with all new fittings/pipes connecting the Water Basket to the main line. More importantly, our design team launched the new and inexpensive plastic "Sin Pauq" (baby
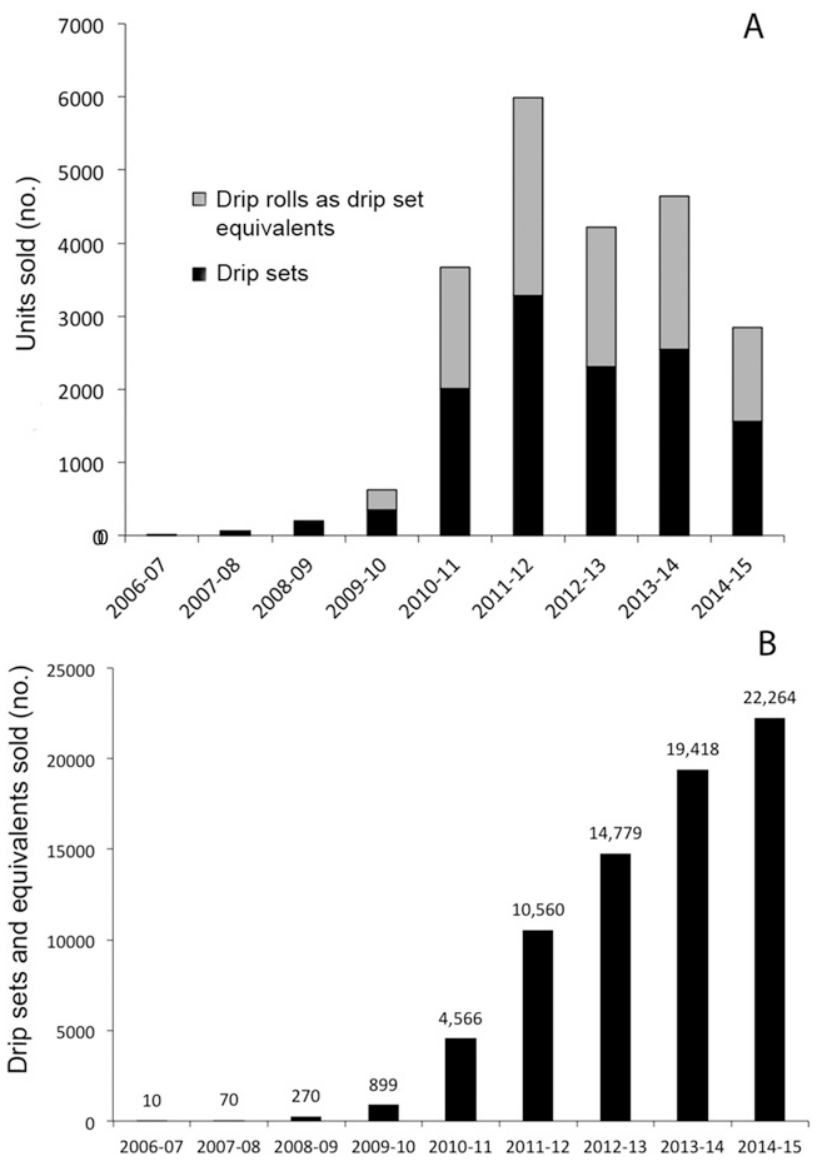

Fig. 11. Annual (A) and cumulative (B) sales of low-pressure drip sets and separate rolls of lateral tubing sold by International Development Enterprises-Myanmar/ Proximity Designs (Yangon, Myanmar) from 2007 to 2015. Sales of separate rolls of lateral tubing are expressed as drip set equivalents: each drip set contains three rolls of lateral tubing; 1 drip set equivalent = total number of separate rolls sold $\div 3$. 
launch meeting at the beginning of the season. It was now clear that drip was a product that was here to stay and that all field staff were expected to actively promote it and conduct at least five onfarm demonstrations in areas where drip had not been used before.

The provision of product loans was also closely associated with this season's expansion with over $70 \%$ of drip systems purchased with loans administered by the same field staff who were promoting and installing drip. About this time, self-employed, independent village "agents" began doing drip installations for small fees in some areas; sales were also boosted as a result of our first serious efforts to train these agents who in the past did only treadle pump installations. Many of them installed drip on their own plots after learning how to set up and operate a small system during their training program in Yangon. Given proper hands-on training, agents often became the first adopters in their communities where they were known and trusted. Nearly all were farmers themselves and helped begin the process of farmer-to-farmer observation and discussion, which resulted in further adoption without the same level of promotional efforts required by our full-time staff. They no doubt multiplied the capacity of full-time field staff and were key players in the expansion of drip.

Acceptance and adaptation, 2011-14. New drip system sales rose again in the 2011-12 dry season to over 3200 sets, although the increase was smaller than the previous season's expansion, perhaps as a result of a decline in the easy availability of product loans. However, this season saw a large increase in sales of separate rolls of drip lateral tubing; 4800 rolls of lateral tubing, equivalent to the area of 1600 drip sets, were sold in 2011-12 (Fig. 11A) for expansion of older systems or for larger installations using motorized pumpsets. At this time, inexpensive 4- to 5 -horsepower gasoline pumps ( $\$ 100$ to $\$ 125$ ) began to appear in Yangon markets, and we began getting requests from staff to help customers configure our drip components for larger, higherpressure systems.

New drip set sales declined somewhat in 2012-13 following introduction of the 2-inch layflat and subsequent price increase when the main/submain pipe was included in the set for the first time. Sales of new sets rose again in 2013-14 followed by what could be a decline in the current (2014-15) season, although this season's sales figures were incomplete at the time of writing; Proximity Design's 2014-15 drip set price was $\$ 37.50$. Although it is too early to say with any certainty, sales of packaged drip sets might be declining while sales of separate rolls of drip lateral tubing are static or increasing (Fig. 11A). This could be associated with the rapid drop in treadle pump and Water Basket sales as farmers move from gravity-fed systems to inexpensive motorized pumpsets (Proximity Designs, unpublished data).

Careful attention to appropriate design of all major components and private sector sales coupled with a strong on-farm demonstration and farmer education program resulted in adoption of drip in almost all agroclimatic zones in the country with over 12,000 small farm drip systems installed since 2008 plus the equivalent of another 10,000 sets in separate sales of drip lateral tubing (Fig. llB).

\section{Conclusions and lessons learned}

On the basis of hundreds of controlled tests and on-farm demonstrations conducted from 2006 to 2012, we developed a robust small farm drip irrigation system simple enough to be manufactured in Myanmar at low cost. Large enough for use on $4000 \mathrm{ft}^{2}$ commercial plantings of flowers, fruits, and vegetables, the Myanmar drip set in its simplest form can function at pressures as low as $1-2$ psi or $\approx 1 / 10$ th of conventional drip operating pressures.

We created a market for not only a new product, but also an entirely new system of irrigation in Myanmar. Our drip systems have been used on a wide range of crops including 16 different vegetables, 14 fruit crops, 5 flower and ornamental crops, and 7 crops grown for other uses such as betel leaf, coffee (Coffea arabica), and a perfume crop. While refining each component to function well using very low system pressure was important, this did not ensure success; successful introduction required long-term and aggressive extension and training programs. It is also doubtful that a drip system in the Myanmar context would have been successful during the first decade of the 2000 s without concurrent efforts by our design and manufacturing teams to develop affordable water containers and inexpensive and easily elevated treadle pumps to fill those containers.

In our experience, the concept of drip irrigation was just as difficult to sell as the hardware, at least in the beginning. We devoted considerable time and resources to develop training aids and tools which helped change perceptions and simplified/explained the technology to both staff and farmers unfamiliar with it. These included five illustrated extension guides, two water requirement calculators, and seven videos (DVDs) published by IDE/Proximity Designs from 2009 to 2013 . Scaling up required an extensive network of dedicated, field-based promotion (extension) staff and private agents who could comfortably explain and demonstrate the technology in areas where it was previously unknown. Strong perceptual barriers were overcome with effective practical staff training and many on-farm demonstrations (experiencing is believing). It was especially important that these staff ensured success of the first adopters so that subsequent farmer-to-farmer diffusion could occur.

Often overlooked is the level of technical support/expertise required in such programs. This includes the ability to train key staff and counterparts, to solve problems as they inevitably arise, to experiment with system changes and to help produce appropriate educational tools and materials in support of on-farm demonstration and training programs.

The importance of product loans or other farm credit cannot be underestimated, especially in countries like Myanmar where farmers have little access to low-interest agricultural loans. Although time consuming and difficult to manage, the product loans made available to our customers after 2009 accelerated adoption and helped ensure more equitable access to the technology.

IDE/Proximity Design's history of introducing drip in Myanmar was initially one of slow growth: we tested, improved, and demonstrated custom systems built with imported pieces and parts while gradually substituting locally made components as they were designed and manufactured. Only in the final stages were drip sets or kits 
assembled and marketed with all locally made components. We learned during the first season that wholesale importation of "drip kits" designed for an entirely different agricultural context was inappropriate.

It will be interesting to see how newly imported commercial drip systems will fare in the country following the recent lifting of trade sanctions and whether they will be affordable to smallholder farmers. It is likely that microtube systems like ours will eventually be displaced although questions remain regarding clog resistance of built-in labyrinth flow path emitter tapes under extremely low pressures and relatively poor filtration from simple screen filters. However, this might not be an issue if most Myanmar farmers are transitioning to motorized pumping systems.

Drip irrigation is still in its early adoption stages in many parts of the country and a generation may be required before the technology is well known and widespread. This poses a challenge to donors expecting quick results and impact from social enterprises introducing new irrigation technologies to raise small farm incomes. Any organization or company hoping to introduce drip in a country where it was previously unknown should be prepared for a long-term commitment. This was also the case with small farmers in Kentucky where drip irrigation became common among horticultural crop growers only after a decade of well-supported on-farm demonstrations by the Cooperative Extension Service.

It is hoped that lessons learned and described here will help shorten the time and effort required to introduce low-cost drip in similar socioeconomic settings. Adoption may accelerate in Myanmar as private companies begin marketing imported or locally manufactured irrigation products, although the challenge will still be to design and demonstrate simple, flexible, effective, and intuitive systems that are affordable to smallholder farmers. In the meantime, ultra-lowpressure drip systems are now being tested in conjunction with low-powered direct-current pumps and solar (photovoltaic) panels for horticultural crops in India, Nepal, Myanmar, and with high tunnels in Kentucky.

\section{Literature cited}

Chapin Watermatics. 1971. Drip irrigation growing in San Diego County. Western Grower Shipper.

Commodity Growers Cooperative Association. 1998. Pumpkin patches on tobacco road: Improving horticultural and other farm product opportunities in tobacco communities. Commodity Growers Coop. Assn., Lexington, KY.

Cote, C.M., K.L. Bristow, P.B. Charlesworth, F.J. Cook, and P.J. Thorburn. 2003. Analysis of soil wetting and solute transport in subsurface trickle irrigation. Irr. Sci. 22:146-156.

Das, B., P. Hazarika, G. Saikia, H. Kalita, D.C. Goswami, H.B. Das, S.N. Dube, and R.K. Dutta. 2007. Removal of iron by groundwater by ash: A systematic study of a traditional method. J. Hazard. Mater. 141:834-841.

Fandika, I.R., D. Kadyampakeni, and S. Zingore. 2012. Performance of bucket drip irrigation powered by treadle pump on tomato and maize/bean production in Malawi. Irr. Sci. 30:57-68.

Hanson, B.R., D.E. May, J. Simnek, J.W. Hopmans, and R.B. Hutmacher. 2009. Drip irrigation provides salinity control needed for profitable irrigation of tomatoes in the San Joaquin Valley. Calif. Agr. 63:131-136.

Keller, J., D.L. Adhikari, M. Petersen, and S. Suryawanshi. 2001. Engineering lowcost micro-irrigation for small plots. Rpt. No. 5. Intl. Development Enterprises, Denver, CO.

Keller, J. 2002. Evolution of drip/micro irrigation: Traditional and non-traditional uses. Intl. Mtg. on Advances in Drip/ Micro Irrigation, 2-5 Dec. 2002, Tenerife, Spain.

Lamont, W. 2012. Maintaining drip irrigation systems. 21 May 2015. <http:// extension.psu.edu/plants/vegetablefruit/news $/ 2012 /$ maintaining-dripirrigation-systems $>$.

Locascio, S.J. 2005. Management of irrigation for vegetables: Past, present, and future. HortTechnology 15:482-485.

Maung Maung Yi. 2009. Importance, production, consumption, and development of vegetables in Myanmar. Proc. Wkshp.
Vegetables for Sustainable Food and Nutritional Security, FAO, Myanmar, p. 19-30.

National Research Council. 2010. Toward sustainable agricultural systems in the 21st century. National Academy Press, Washington, DC.

Ngigi, S. 2008. Technical evaluation and development of low-head drip irrigation systems in Kenya. Irr. Drain. 57:450-462.

Palada, M., S.P. Bhattarai, M.S. Roberts, M. Bhattarai, N. Baxter, R. Kimsan, and D.L. Wu. 2011. Improving smallholder dry season vegetable production through increased water productivity with low cost drip irrigation technology in Cambodia. Acta Hort. 922:133-140.

Palada, M. and M. Bhattarai. 2012. Assessing technology and socioeconomic constraints and prospects of low-cost drip irrigation for vegetable farming in Southeast Asia, p. 154-167. Proc. High Value Vegetables in Southeast Asia (SEAVEG): Production, Supply, and Demand. 21 May 2015. <http://203.64. 245.61/fulltext_pdf/EB/2011-2015/ eb0197.pdf>.

Rowell, B. (ed.). 1999. Fruit and vegetable crops research report. Univ. Kentucky, Dept. Hort., Publ. PR-423. 21 May 2015. <http://www2.ca.uky.edu/agc/ pubs/pr/pr423/pr423.htm>.

Rowell, B. and M.L. Soe. 2009. Easy watering in six steps: Drip irrigation installation guide. Intl. Development Enterprises-Myanmar, Yangon, Myanmar.

Rowell, B. and M.L. Soe. 2012. Easy watering in six steps: Drip irrigation installation guide. 4th ed. Proximity Designs, Yangon, Myanmar.

Settheeworrarit, T., S.K. Hartwell, S. Lapanatnoppakhun, J. Jakmunee, G.D. Christian, and K. Grudpan. 2005. Exploiting guava leaf extract as an alternative natural reagent for flow injection determination of iron. Talanta 68:262267.

Smeal, D., M.W. West, Z.F. Williams, M.K. O'Neill, K. Lombard, and R.N. Arnold. 2008. Efficient irrigation of small plots using a simple, inexpensive microirrigation system. 27 May 2015. <http:// irrigationmanagement.nmsu.edu/ documents/proceedings-icasals 2006. pdf $>$. 